(2) Open Access Full Text Article

REVIEW

\title{
Inotuzumab ozogamicin in the treatment of relapsed/refractory acute $B$ cell lymphoblastic leukemia
}

This article was published in the following Dove Press journal: Journal of Blood Medicine

\section{Natalie Uy \\ Michelle Nadeau \\ Maximilian Stahl \\ Amer M Zeidan}

Section of Hematology, Department of Internal Medicine, Yale School of Medicine, New Haven, CT, USA
Correspondence: Amer M Zeidan Section of Hematology, Department of Internal Medicine, Yale School of Medicine, 333 Cedar Street, New Haven, CT 06520-8028

Email amer.zeidan@yale.edu

\begin{abstract}
The improvement in outcomes of adult patients with acute lymphoblastic leukemia (ALL) has been modest, with the exception of Philadelphia chromosome-positive disease, despite advances in supportive care and stem cell transplantation. The recent approvals of novel agents, including the bispecific T-cell engager blinatumomab, the antibody-drug conjugate inotuzumab ozogamicin, and chimeric antigen receptor T-cell products are changing the management of B-ALL, which traditionally relied on chemotherapy-based approaches. Inotuzumab ozogamicin is a humanized CD22 monoclonal antibody linked to the cytotoxic agent calicheamicin. CD22 is expressed on leukemic blasts in $>90 \%$ of ALL patients, and inotuzumab ozogamicin has shown excellent clinical activity even among heavily pretreated relapsed/refractory $(R / R)$ B-ALL patients and elderly B-ALL patients. Clinical trials have shown superior survival with the drug over chemotherapy-based approaches in the first- or second-line salvage therapy for relapsed B-ALL as monotherapy. Currently, new trials are evaluating inotuzumab ozogamicin in the frontline setting in combination-based approaches. In this review, we summarize the preclinical and clinical data of inotuzumab ozogamicin in R/R B-ALL and foresee the future use of this drug in the clinic.
\end{abstract}

Keywords: inotuzumab ozogamicin, CD22, monoclonal antibodies, acute lymphoblastic leukemia, antibody-drug conjugate

\section{Introduction}

Acute lymphoblastic leukemia (ALL) is diagnosed predominantly in children, but $20 \%$ of patients are adults, with an incidence estimated at 1.6 per 100,000 population in a bimodal distribution. ${ }^{1}$ ALL is divided into B-cell (B-ALL) and T-cell ALL (T-ALL). B-ALL can be Philadelphia chromosome positive/BCR-ABL $(\mathrm{Ph}+)$ or Philadelphia chromosome negative $(\mathrm{Ph}-){ }^{2}$ These distinctions are important because prognosis and treatment varies for these different classes of ALL. The aim of induction treatment is to achieve remission, followed by consolidation/maintenance therapy in standard-risk patients and allogeneic hematopoietic cell transplantation (HSCT) in high-risk patients. Chemotherapy regimens have been highly successful in the pediatric ALL, and the pediatric approach of induction, consolidation, maintenance, and CNS prophylaxis has since been applied to adult ALL. ${ }^{3}$ Survival of adult patients with ALL has modestly improved with new chemotherapy regimens, better supportive care, and wider use of HSCT for patients, but outcomes remain poor in adults. Although $80 \%-90 \%$ of adult patients achieve complete response (CR), most still relapse; cure rates occur only at $40 \%$ in first salvage and less than $10 \%-20 \%$ in later salvages. ${ }^{4-6}$ Because achieving $\mathrm{CR}$ is 
crucial for successful HSCT, adults with relapsed/refractory $(\mathrm{R} / \mathrm{R}) \mathrm{B}-\mathrm{ALL}$ often cannot proceed to transplantation, the only potentially curative option after salvage treatment. Current adult ALL therapy is already associated with significant toxicities, especially in older patients, limiting further intensification of therapy. ${ }^{5}$

Thus, the introduction of novel therapies such as monoclonal antibodies and chimeric antigen receptor T-cell (CAR T-cell) products is changing the management landscape of the B-ALL, which traditionally heavily relied on chemotherapybased approaches. Monoclonal antibodies can be a naked antibody, bispecific T-cell engagers (BiTEs), or antibodydrug conjugate (ADCs)/immunoconjugates; their cytotoxic mechanisms can occur via antibody-dependent cellular cytotoxicity, complement-dependent cytotoxicity, or direct induction of cell death as vehicles to cytotoxic molecules internalized into the cell. In CAR T-cell therapy, T cells are collected from a patient, modified to recognize antigens on targeted cells, and infused back into the patient. ${ }^{1,7}$ These new techniques have changed the landscape of salvage therapy in ALL.

Inotuzumab ozogamicin is a novel monoclonal antibody against CD22 conjugated to the toxin calicheamicin. Inotuzumab ozogamicin has been shown to improve outcomes in $\mathrm{R} / \mathrm{R}$ ALL and was approved for use as monotherapy in this setting. Ongoing studies are evaluating inotuzumab ozogamicin in combination with cytotoxic chemotherapy in the frontline and salvage settings. ${ }^{8}$ This review will discuss inotuzumab ozogamicin, providing an overview on mechanisms and pharmacokinetics, outcomes in preclinical and clinical trials, and future directions for research. In this review, we attempted to cover the most comprehensive collection of trials to date, aiming to give updates from prior literature reviews on inotuzumab ozogamicin. ${ }^{6,8}$ While inotuzumab ozogamicin has been reviewed in context of multiple malignancies, this review will highlight advances in ALL specifically.

\section{Inotuzumab ozogamicin Mechanism of action}

Inotuzumab ozogamicin is a humanized anti-CD22 immunoglobulin G4 (IgG4) monoclonal antibody bound via a bifunctional linker to calicheamicin, a potent cytotoxic agent derived from the natural bacterium product of Micromonospora echinospora. Calicheamicin induces DNA double-strand breaks and apoptosis independent of cell cycle progression, making it strategic for targeting malignant cells with similar proliferation rates compared with normal cells. ${ }^{6,9,10}$
CD22 is a B-cell-specific transmembrane sialoglycoprotein involved in B-cell activation and regulation. CD22 expression is restricted to B-cell lineage, and CD22 interacts with diverse sialic acid-bearing molecules present on various cell types, including B and T cells, neutrophils, and monocytes. CD22 has been hypothesized to regulate signal transduction of the surface immunoglobulin receptors on $B$ cells, B-cell migration, and maintenance of peripheral B-cell tolerance. ${ }^{9}$ CD22 is expressed primarily intracellularly during the early stages of B-cell development, including pro-B and pre-B cells, and this expression shifts to the transmembrane with increasing B-cell maturity. ${ }^{9} \mathrm{CD} 22$ is most highly expressed in mature B cells and is expressed by most B-cell malignancies, including B-ALL, non-Hodgkin lymphoma (NHL), chronic lymphocytic leukemia, and hairy cell leukemia. In particular, CD22 is expressed on leukemic blasts in $>90 \%$ of ALL patients. ${ }^{9}$

Upon binding to $\mathrm{CD} 22$ receptors at the cell surface of $\mathrm{B}$ cells, the inotuzumab-calicheamicin complex is rapidly internalized as an ADC. An acid-labile, hydrazone-based linker and a stabilized disulfide linker allow the release of the prodrug calicheamicin in the intracellular environment, preventing premature activation. ${ }^{9}$ Once internalized, the ADC is trafficked through endosomes and lysosomes, where the acidic lysosome environment leads to hydrolysis of inactive calicheamicin from the inotuzumab antibody. Intracellular glutathione then reduces calicheamicin to its active form; once internalized to the nucleus, active calicheamicin binds to the minor grove of DNA and generates free radicals, causing DNA double-strand breaks and cellular apoptosis (Figure 1). ${ }^{9,11}$ Inotuzumab, therefore, allows for targeted delivery of a cytotoxic drug to malignant cells overexpressing CD22 with minimal toxicity to normal tissues that lack CD22 expression, including hematopoietic stem cells and other nonlymphoid lineages.

\section{Pharmacokinetics}

Pharmacokinetic analysis of inotuzumab ozogamicin in original Phase I studies suggests that inotuzumab ozogamicin displays nonlinear pharmacokinetics. Total drug exposure for both inotuzumab and calicheamicin measured by area under the concentration (AUC) and peak observed concentration $\left(C_{\max }\right)$ increases with cumulative dose of inotuzumab ozogamicin and repeated dosing. ${ }^{12}$ Inotuzumab ozogamicin induces dose and time-dependent cell death $\left(\mathrm{IC}_{50}\right.$ ranged from 0.15 to $4.9 \mathrm{ng} / \mathrm{mL}$ ) in various ALL cell lines. ${ }^{11}$ Calicheamicin demonstrates a longer half-life than inotuzumab. ${ }^{13}$ Singledose inotuzumab ozogamicin is associated with higher peak 


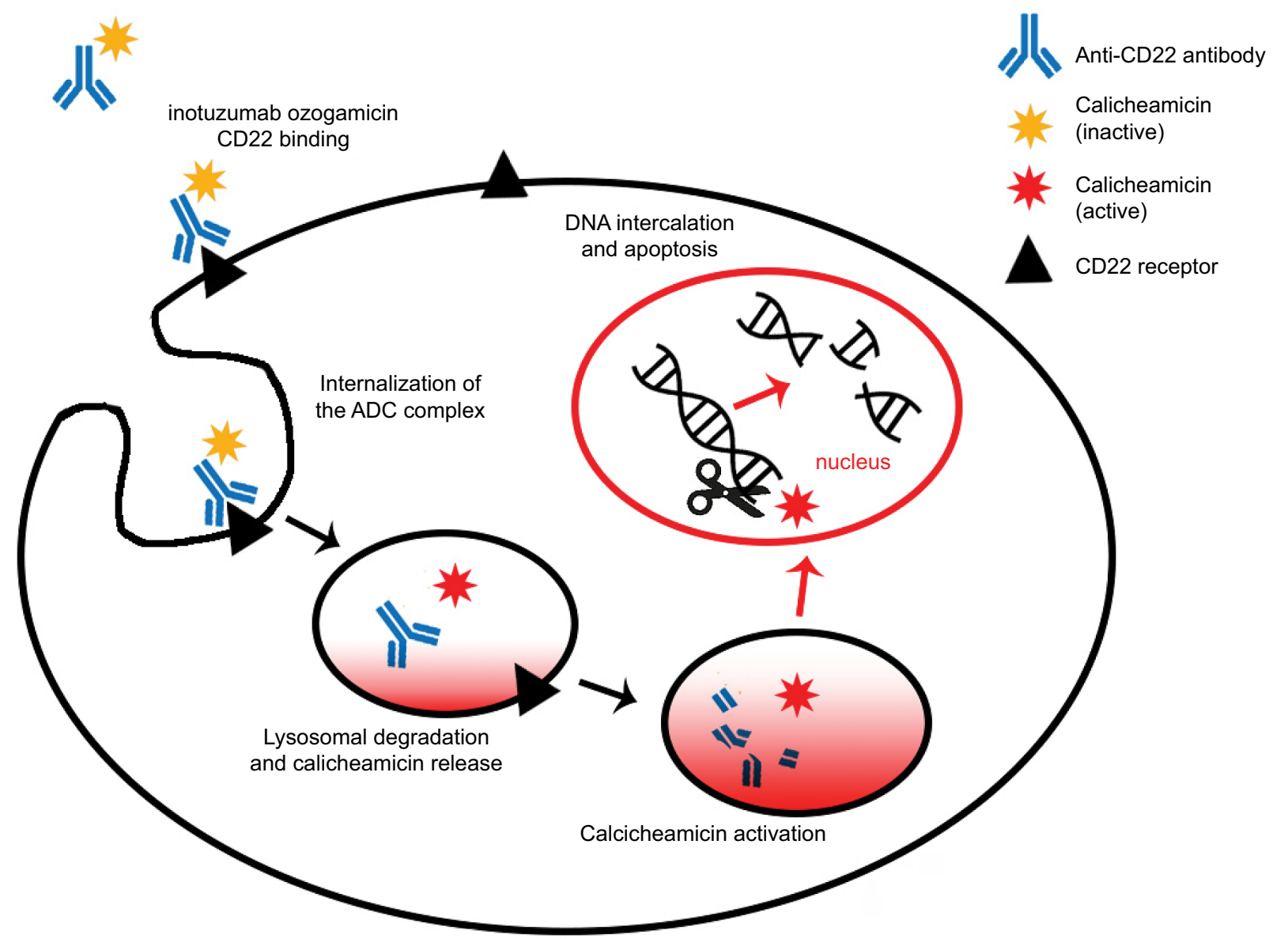

Figure I Mechanism of inotuzumab ozogamicin.

Notes: Inotuzumab ozogamicin binds to the CD22 receptor of B cells and is internalized as a CD22-ADC complex. It is trafficked from endosome to lysosome with decreasing $\mathrm{pH}$ from 6 to 4 , leading to degradation of an acid labile linker. This leads to the release and activation of the toxin calicheamicin as the antibody degrades. In the nucleus, calicheamicin intercalates in DNA, leading to apoptosis in targeted cells.

Abbreviation: ADC, antibody-drug conjugate.

levels as compared to weekly dosing. However, this does not translate to improved response rates. ${ }^{14}$ Furthermore, analysis of CD22 receptor saturation within ALL cells suggests prolonged continuous exposure to inotuzumab ozogamicin achieved by the weekly dosing administration mediates more effective cell killing. ${ }^{11,14}$

\section{Clinical data on inotuzumab ozogamicin for B-ALL Inotuzumab ozogamicin preclinical studies}

Inotuzumab ozogamicin (known as CMC-544 in preclinical studies) has been evaluated in multiple types of hematologic malignancies. ${ }^{15}$ As previous studies demonstrated antitumor activity against $\mathrm{CD} 22^{+} \mathrm{B}$-cell lymphoma xenografts, Dijoseph et al tested inotuzumab ozogamicin in mice with established ALL xenografts. Inotuzumab ozogamicin caused dose-dependent inhibition of xenograft growth, producing complete tumor regression and even cures in tumor-bearing mice. ${ }^{16}$
Compared to acute myeloid leukemia and NHL, ALL cell lines were actually more sensitive to calicheamicin-induced apoptosis. ${ }^{11}$ Sensitivity to calicheamicin rather than saturation of CD22 cell surface expression was the major determinant for inotuzumab ozogamicin's efficacy. Therapeutic potential of inotuzumab ozogamicin in ALL was investigated in pre-B-ALL xenografts growing subcutaneously or as disseminated tumors in mice. Inotuzumab ozogamicin inhibited tumor growth, and mice were considered cured based on the observation period. Of note, ALL cell lines exhibited greater sensitivity than B-cell lymphoma-derived cell line. ${ }^{11}$ Given results of these experiments, inotuzumab ozogamicin generated great interest in its potential use as an option for treating relapsed ALL.

\section{Inotuzumab ozogamicin monotherapy in B-ALL}

On the basis of results from pre-clinical trial experience and Phase I studies, mostly in lymphomas, ${ }^{11,12}$ several Phase II 
studies were conducted to evaluate the safety and efficacy of inotuzumab ozogamicin in treating relapsed B-ALL. An open-label, nonrandomized, single-center trial was conducted at MD Anderson Cancer Center in patients with confirmed R/R B-ALL. Patients received single-dose inotuzumab ozogamicin $1.3-1.8 \mathrm{mg} / \mathrm{m}^{2}$ once every $21-28$ days (Table 1). ${ }^{5}$ Repeat courses of treatment were determined by count recovery and bone marrow assessment of disease. If persistent disease was noted on bone marrow biopsy, patients received additional courses of inotuzumab ozogamicin regardless of peripheral blood counts. Patients achieving CR after 1-2 courses of inotuzumab ozogamicin continued treatment up to 4 cycles, and further treatment was determined by continued response and toxicities experienced with previous doses. ${ }^{5}$
To improve efficacy and reduce toxicities, a later cohort of patients received a modified schedule of weekly inotuzumab at a dose of $0.8 \mathrm{mg} / \mathrm{m}^{2}$ administered on day 1 followed by 0.5 $\mathrm{mg} / \mathrm{m}^{2}$ on days 8 and 15 repeated every $21-28$ days. Thus, the study was expanded to a total of 90 patients with the abovementioned 49 patients treated with single-dose inotuzumab ozogamicin plus 41 patients treated with weekly inotuzumab ozogamicin. ${ }^{14}$ The median age of the patients was 39.5 years including 6 patients $(7 \%) \leq 18$ years of age. All patients expressed CD22 positively in at least $50 \%$ of B cells, and $17 \%$ were $\mathrm{Ph}+\mathrm{B}-\mathrm{ALL}$. Eleven percent of patients received prior treatment with HSCT, and $63 \%$ of patients received prior treatment with HyperCVAD. ${ }^{14}$ Overall, 17 patients (19\%) achieved a CR and overall response rate (ORR) was $58 \%$. Similar response rates were noted between both dosing

Table I Summary of clinical trials of inotuzumab ozogamicin in ALL patients

\begin{tabular}{|c|c|c|c|c|c|c|c|c|c|}
\hline Study & Phase & Cohort & $\mathbf{N}$ & Dosing & $\begin{array}{l}\text { CD22 } \\
\text { positivity }\end{array}$ & ORR & CR & CRi & Median OS \\
\hline \multicolumn{10}{|c|}{ Monotherapy } \\
\hline $\begin{array}{l}\text { Kantarjian } \\
\text { et al, } 2012^{5}\end{array}$ & Phase II & $\begin{array}{l}\text { Adults and } \\
\text { children with } \\
\text { R/R ALL }\end{array}$ & 49 & $\begin{array}{l}\mathrm{I} .3-1.8 \mathrm{mg} / \mathrm{m}^{2} \mathrm{q} 3-4 \\
\text { weeks }\end{array}$ & $>50 \%$ & $57 \%$ & $9 / 49(18 \%)$ & $4 / 49(8 \%)$ & $\begin{array}{l}7.9 \text { months } \\
\text { (responders) }\end{array}$ \\
\hline $\begin{array}{l}\text { Kantarjian } \\
\text { et al, } 2013^{14}\end{array}$ & Phase II & R/R ALL & 90 & $\begin{array}{l}\mathrm{I} .3-\mathrm{I} .8 \mathrm{mg} / \mathrm{m}^{2} \\
\mathrm{q} 3-4 \text { weeks OR } \\
0.8 \mathrm{mg} / \mathrm{m}^{2} \text { (day I), then } \\
0.5 \mathrm{mg} / \mathrm{m}^{2} \text { (days } 8 \text { and I5) } \\
\text { q3-4 weeks }\end{array}$ & $>50 \%$ & $58 \%$ & $17 / 90(19 \%)$ & $8 / 90(19 \%)$ & 6.2 months \\
\hline $\begin{array}{l}\text { Advani et al, } \\
2014^{17}\end{array}$ & Phase II & R/R ALL & 35 & $\begin{array}{l}0.8 \mathrm{mg} / \mathrm{m}^{2} \text { (day I), then } \\
0.5 \mathrm{mg} / \mathrm{m}^{2} \text { (days } 8 \text { and } \mathrm{I} 5 \text { ) }\end{array}$ & $99 \%$ & $\begin{array}{l}(\mathrm{CR}+\mathrm{CRi}) \\
23 / 35(66 \%)\end{array}$ & $1 \mathrm{I} / 35(3 \mathrm{l} \%)$ & $12 / 35(34 \%)$ & 7.4 months \\
\hline $\begin{array}{l}\text { Kantajian } \\
\text { et al, } 2016^{18}\end{array}$ & Phase III & R/R ALL & 326 & $\begin{array}{l}0.8 \mathrm{mg} / \mathrm{m}^{2} \text { (day I), then } \\
0.5 \mathrm{mg} / \mathrm{m}^{2} \text { (days } 8 \text { and } 15 \text { ) } \\
\text { q3-4 weeks vs standard } \\
\text { chemo (investigator's } \\
\text { choice) }\end{array}$ & $\begin{array}{l}74 / 109 \\
(68 \%) \\
>90 \% \\
\text { CD22 } \\
\text { positive }\end{array}$ & $\begin{array}{l}88 / 109(81 \%) \\
(1 O) \text { vs } \\
32 / 109(29 \%) \\
\text { (standard) } \\
p<0.001\end{array}$ & $\begin{array}{l}39 / 109(36 \%) \\
(10) \text { vs } \\
19 / 109(17 \%) \\
\text { (standard) } \\
p=0.002\end{array}$ & $\begin{array}{l}49 / 109(45 \%) \\
\text { (IO) vs } \\
13 / 109(12 \%) \\
\text { (standard) } \\
p<0.00 \text { I }\end{array}$ & $\begin{array}{l}7.7 \text { months } \\
\text { (IO) vs } \\
6.7 \text { months } \\
\text { (standard) }\end{array}$ \\
\hline \multicolumn{10}{|c|}{ Combination therapy } \\
\hline $\begin{array}{l}\text { Jabbour } \\
\text { et al, } 2015^{24}\end{array}$ & Phase II & $\begin{array}{l}\text { Frontline, } \\
>60 \text { years }\end{array}$ & 34 & $\begin{array}{l}\text { Mini-hyper-CVD + IO } \\
\left(1.8 \mathrm{mg} / \mathrm{m}^{2} \text { for cycle I }\right. \\
\text { followed by } 1.3 \mathrm{mg} / \mathrm{m}^{2} \text { for } \\
\text { subsequent cycles })\end{array}$ & $97 \%$ & $30 / 31(97 \%)$ & $25 / 31$ (8I\%) & $\begin{array}{l}5 / 3 \mid(3 \mid \%) \\
(\mathrm{CRp})\end{array}$ & $\begin{array}{l}70 \%(2 \text { year } \\
\text { OS) }\end{array}$ \\
\hline $\begin{array}{l}\text { Sasaki et al, } \\
2016^{20}\end{array}$ & Phase II & R/R ALL & 57 & $\begin{array}{l}\text { Mini-hyper-CVD + IO } \\
\left(1.8 \mathrm{mg} / \mathrm{m}^{2} \text { for cycle I }\right. \\
\text { followed by } 1.3 \mathrm{mg} / \mathrm{m}^{2} \text { for } \\
\text { subsequent cycles) }\end{array}$ & $96 \%$ & $45 / 59(54 \%)$ & $31 / 57(52 \%)$ & $1 / 57(2 \%)$ & $\begin{array}{l}34 \% \text { ( } 2 \text { year } \\
\text { OS) }\end{array}$ \\
\hline $\begin{array}{l}\text { Jabbour } \\
\text { et al, 2018 }\end{array}$ & Phase II & R/R ALL & 59 & $\begin{array}{l}\text { Mini-hyper-CVD + IO } \\
\left(1.3-1.8 \mathrm{mg} / \mathrm{m}^{2} \text { for cycle }\right. \\
\text { I followed by } 1.0-1.3 \mathrm{mg} / \\
\left.\mathrm{m}^{2} \text { for subsequent cycles }\right)\end{array}$ & $95 \%$ & $46(78 \%)$ & $35 / 59(59 \%)$ & I/59 (2\%) & II months \\
\hline $\begin{array}{l}\text { Kantarjian } \\
\text { et al, } 2018^{22}\end{array}$ & Phase III & $\begin{array}{l}\text { Frontline, }>60 \\
\text { years }\end{array}$ & 52 & $\begin{array}{l}\text { Mini-hyper-CVD + IO } \\
\left(1.8 \mathrm{mg} / \mathrm{m}^{2} \text { for cycle I }\right. \\
\text { followed by } 1.3 \mathrm{mg} / \mathrm{m}^{2} \text { for } \\
\text { subsequent cycles })\end{array}$ & $97 \%$ & $47 / 48(98 \%)$ & $4 \mathrm{I} / 48(85 \%)$ & $5 / 48(10 \%)$ & $\begin{array}{l}66 \%(2 \text {-year } \\
\text { OS) }\end{array}$ \\
\hline
\end{tabular}

Abbreviations: $\mathrm{CR}$, complete response; CRi, complete response with incomplete recovery of peripheral blood counts; CRp, complete response with incomplete recovery of platelets; IO, inotuzumab ozogamicin; ORR, overall response rate; OS, overall survival; R/R, relapsed/refractory; ALL, acute lymphoblastic leukemia. 
schedules of inotuzumab ozogamicin. Of note, weekly dosing led to lower rates of side effects, including drug-related fever, hypotension, hyperbilirubinemia, and elevated liver enzymes. Patients receiving inotuzumab ozogamicin as second-line salvage treatment or greater $(48 \%-50 \%$ vs $76 \%$ for first-line salvage treatment; $p=0.056)$ as well as patients with Ph+B-ALL (40\% vs 57\%-81\%; $p=0.047$ ) were noted to have lower response rates. The median overall survival (OS) was 5.0 vs 7.3 months for the single-dose and weekly dosing cohorts of inotuzumab ozogamicin, respectively, for an OS of 6.2 months. $^{14}$

Weekly inotuzumab ozogamicin was also evaluated in relapsed B-ALL patients in a Phase II study by Advani et al (Table 1). Patients with relapsed CD22-positive B-ALL received inotuzumab ozogamicin at a dose of $0.8 \mathrm{mg} / \mathrm{m}^{2}$ on day 1 followed by $0.5 \mathrm{mg} / \mathrm{m}^{2}$ on days 8 and 15 every 28 days for up to 6 cycles. Patients achieving CR or complete response with incomplete recovery of peripheral blood counts (CRi) transitioned to a dose reduced $1.6 \mathrm{mg} / \mathrm{m}^{2} /$ cycle schedule. Thirty-five patients were enrolled to receive treatment; the median age of the patients was 34 years; all patients were $\geq 18$ years of age. Overall expression of CD22 on B cells was $99 \%$, and $26 \%$ of patients expressed $\mathrm{Ph}+$ B-ALL. Fifteen patients (43\%) received prior treatment with HSCT and all patients received inotuzumab ozogamicin as second-line salvage treatment or greater. Overall, 11 patients (31\%) achieved CR and 12 patients (34\%) achieved CRi for an ORR of $66 \%$. The median OS was 7.4 months. The most commonly reported grade $\geq 3$ adverse effects (AEs) included febrile neutropenia (20\%), thrombocytopenia (31\%), transaminitis $(6 \%)$, and veno-occlusive disease (VOD) $(8.5 \%) .{ }^{17}$

Inotuzumab ozogamicin has been compared against standard intensive chemotherapy in an open-label, randomized, Phase III trial (INO-VATE trial; Table 1). ${ }^{18}$ Patients with $\mathrm{R} / \mathrm{R}$ CD22-positive B-ALL randomized to the inotuzumab ozogamicin arm received a modified weekly schedule of inotuzumab ozogamicin $-0.8 \mathrm{mg} / \mathrm{m}^{2}$ administered on day 1 and $0.5 \mathrm{mg} / \mathrm{m}^{2}$ administered on days 8 and 15 repeating every 21-28 days. The day 1 dose of inotuzumab ozogamicin was further dose reduced to $0.5 \mathrm{mg} / \mathrm{m}^{2}$ if patients achieved CR or CRi. Patients randomized to the standard-therapy group received FLAG (fludarabine, cytarabine, and granulocytecolony-stimulating factor), high-dose cytarabine, or mitoxantrone plus cytarabine. Primary end points included CR and OS. ${ }^{18}$ A total of 326 patients were randomized, with 109 in each group for the primary intention-to-treat analysis. The majority of patients in the inotuzumab ozogamicin (68\%) and standard-therapy (58\%) groups expressed CD22 positivity in
$>90 \%$ of B cells. Duration of first remission was $<12$ months for $57 \%$ of inotuzumab ozogamicin patients and $65 \%$ of standard-therapy patients, with a majority of patients in both groups receiving only one prior induction therapy. Sixteen percent of inotuzumab ozogamicin vs $20 \%$ of standardtherapy patients had received prior HSCT.

Overall, the CR rate was higher for the inotuzumab ozogamicin group compared with the standard-therapy group $(80.7 \%$ vs $29.4 \% ; p<0.001)$. The rate of CR was higher in the inotuzumab ozogamicin group compared with the standardtherapy group for all stratification factors at randomization including age, duration of first remission, salvage-treatment phase, and baseline patient characteristics except for $\mathrm{Ph}$ positive or $\mathrm{t}-(4 ; 11)$ positive disease. Remission duration was significantly longer for the inotuzumab ozogamicin group vs the standard-therapy group (4.6 vs 3.1 months; $p=0.03$ ). Among the patients who achieved CR or $\mathrm{CRi}, 78.4 \%$ of the inotuzumab ozogamicin group had bone marrow blast results below the threshold for minimal residual disease (MRD) vs $28.1 \%$ of standard-therapy group $(p<0.001)$. Further, progression-free survival (PFS) was significantly longer in the inotuzumab ozogamicin group vs the standard-therapy group (5.0 vs 1.8 months; $p<0.001$ ). The median OS was 7.7 vs 6.7 months for the inotuzumab ozogamicin and standardtherapy groups, respectively (Hazard ratio, 0.77 [97.5\% CI, $0.58-1.03] p=0.04$ ) More patients in the inotuzumab ozogamicin group proceeded directly to transplant (41\%) vs in the standard-therapy group $(11 \%, p<0.001) .{ }^{18}$

Older patients from the INO-VATE trial (considered $>55$ years) were further analyzed as a subgroup. ${ }^{19}$ Remission rates and duration were similar, whereas MRD-negativity rates in responders were numerically higher in older patients. Grade $\geq 3$ AEs were more common in patients older than $\geq 55(\mathrm{n}=53)$ vs $<55$ years $(n=86)$ regarding thrombocytopenia $(49 \%$ vs $29 \%$ ), neutropenia ( $53 \%$ vs $42 \%$ ), and febrile neutropenia ( $28 \%$ vs $21 \%$ ), but there were no differences in discontinuation rates in the two age groups (both 17\%). ${ }^{19}$

\section{Inotuzumab ozogamicin combination therapy in ALL}

In addition to monotherapy, inotuzumab ozogamicin has also been studied in the context of combination therapy. In one of the first studies by Jabbour et al, 34 patients $\geq 60$ years of age with newly diagnosed B-ALL received minihyper-CVD (cyclophosphamide and dexamethasone at 50\% dose reduction, no anthracycline, methotrexate at $75 \%$ dose reduction, and cytarabine at $0.5 \mathrm{~g} / \mathrm{m}^{2} \times 4$ doses) plus rituximab and inotuzumab ozogamicin on day 3 of each course of 
treatment. The first cohort of patients received inotuzumab ozogamicin $1.3 \mathrm{mg} / \mathrm{m}^{2}$ for course 1 followed by $0.8 \mathrm{mg} / \mathrm{m}^{2}$ for all subsequent doses. The second cohort of patients received $1.8 \mathrm{mg} / \mathrm{m}^{2}$ for course 1 followed by $1.3 \mathrm{mg} / \mathrm{m}^{2}$ for all subsequent doses. The median age of the patients was 69 years. Of the 31 patients evaluable for response, 30 (97\%) achieved $\mathrm{CR} /$ complete response with incomplete recovery of platelets (CRp) (25 CR, $5 \mathrm{CRp}$ ). The 2-year PFS was $87 \%$. The 2 -year OS rates were $70 \%$, improved compared to the 2-year OS of $38 \%$ using hyper-CVAD chemotherapy (HCVAD) $+/-$ rituximab in similar patient populations in historical trials. ${ }^{4}$ The preliminary results from this trial suggest promising clinical efficacy of inotuzumab ozogamicin as a combination regimen for the frontline treatment of elderly patients with B-ALL. ${ }^{4}$

In another Phase II clinical trial with 57 patients, inotuzumab ozogamicin and mini-hyper-CVD were also evaluated (Table 1). ${ }^{20}$ Rituximab and intrathecal chemotherapy were given for first 4 courses. Inotuzumab ozogamicin was given on day 3 at a dose of $1.8 \mathrm{mg} / \mathrm{m}^{2}$ for cycle 1 and $1.3 \mathrm{mg} / \mathrm{m}^{2}$ for subsequent cycles. The ORR was $54 \%$. Patients who were treated with mini-hyper-CVD plus inotuzumab ozogamicin had higher PFS rates and improved OS compared with prior data on inotuzumab ozogamicin monotherapy in R/R ALL (2-year PFS: $52 \%$ vs $36 \%, p=0.20$; 2 -year OS: $44 \%$ vs $25 \%$, $p=0.01$ ). Notably, 27 (47\%) patients proceeded to receive HSCT, encouraging results for use as a bridging therapy. ${ }^{20}$

In a Phase II study of 59 adults with R/R B-ALL receiving mini-hyper-CVD and inotuzumab ozogamicin, 46 patients (78\% ORR) responded, 35 (59\%) achieving CR. Twenty-six patients (44\%) went on to receive HSCT. The median OS was 11 months. The 1-year OS rates were best for patients treated in first salvage (57\%) and decreased with subsequent salvages $(26 \%-39 \%)$ in the second and third salvages. ${ }^{21}$

Of note, new studies are looking at using inotuzumab ozogamicin for frontline therapy. A single-arm, Phase II trial with 52 patients treated with inotuzumab ozogamicin and mini-hyper-CVD found a 59\% 2-year PFS, which is promising given the limited treatment options in older patients. ${ }^{22}$

\section{Adverse events of inotuzumab ozogamicin}

Inotuzumab ozogamicin was generally well tolerated in clinical studies. When inotuzumab ozogamicin was given at 1.8 $\mathrm{mg} / \mathrm{m}^{2}$ every 3-4 weeks, the most frequent AEs of all grades were drug-related fever (59\%), elevations of liver enzyme concentrations (57\%), increases in bilirubin levels (28\%), and hypotension (26\%); most AE were reversible. Grades
3-4 AEs included drug-related fever and raised bilirubin concentrations. ${ }^{5}$ Of note, the weekly dosing of inotuzumab ozogamicin was better tolerated compared with single-dose inotuzumab ozogamicin with significantly lower rates of grades 1 and 2 side effects, including drug-related fever (7\% vs $41 \% ; p<0.001)$, increased bilirubin ( $5 \%$ vs $24 \% ; p=0.01$ ), and transaminitis $(22 \%$ vs $55 \%$; $p=0.001) .{ }^{14}$ Bilirubin or liver enzyme elevations were all reversible within 1 or 2 weeks. Notably, only 1 of 14 patients on the weekly dosing arm who went to HSCT developed VOD compared with 5 of 22 patients treated with the single-dose strategy. ${ }^{14}$

Peak inotuzumab ozogamicin concentrations were not associated with differences in response rates, while ADC cumulative AUC levels, which were equivalent with weekly and single-dose inotuzumab, were associated with significant differences in marrow response rates. ${ }^{14}$ Thus, the weekly vs single-dose clinical experience supported by the pharmacokinetic studies and clinical studies suggests that weekly inotuzumab ozogamicin may be less toxic without sacrificing efficacy.

In the Phase III randomized controlled trial by Kantarjian et al, the most commonly reported AEs for the inotuzumab ozogamicin vs standard-therapy groups included nausea ( $32 \%$ vs $47 \%$ ), pyrexia ( $27 \%$ vs $43 \%$ ), and febrile neutropenia $(12 \%$ vs $18 \%)$. Cytopenias were also common, although the rate of grade $\geq 3$ thrombocytopenia was lower for the inotuzumab ozogamicin group compared with the standard-therapy group ( $37 \%$ vs $59 \%)$. The rate of liverrelated toxicities was higher among patients treated with inotuzumab ozogamicin compared with standard-therapy including hyperbilirubinemia (15\% vs $10 \%)$ and elevated aminotransferase levels ( $20 \%$ vs $10 \%)$. VOD occurred in $15(11 \%)$ patients treated with inotuzumab ozogamicin vs 1 (1\%) patient treated with standard-therapy. The incidence of VOD was also higher among patients in the inotuzumab ozogamicin group who proceeded to HSCT after the trial compared with the standard-therapy group. Any grade hepatobiliary AE rates were significantly higher in salvage 2 than salvage $1(47 \%$ vs $17 \% ; p<0.001)$ and numerically higher for patients with HSCT compared with those without prior HSCT ( $42 \%$ vs $23 \%$ ). VOD including post-HSCT VOD occurred in $8 \%$ of salvage 1 (with 2 deaths) vs $16 \%$ of salvage 2 patients. VOD occurred in $21 \%$ with vs $9 \%$ without prior HSCT ( 1 death in each cohort). Inotuzumab ozogamicin is effective as salvage 1 and 2 therapies, but hepatotoxicity risk increases with number of prior therapies and prior HSCT. ${ }^{18,23}$ VOD was also seen in 9 patients (15\%) when combined with mini-CVD. ${ }^{21}$ 
In older patients where inotuzumab ozogamicin was used front-line in combination with hyper-mini-CVD, rates of AEs were comparable to prior studies, including prolonged thrombocytopenia (81\%), infections during induction (52\%) and consolidation (69\%), increased aminotransferases $(19 \%)$, hyperbilirubinemia (17\%), and VOD (8\%). There were 6 $(12 \%)$ treatment-related deaths $(5[10 \%]$ from sepsis and 1 $[2 \%]$ from VOD). ${ }^{22}$

\section{Future directions}

Combining inotuzumab ozogamicin with some of the current standard-of-care regimens for the treatment of B-cell malignancies or replacing components of chemotherapy regimens with inotuzumab ozogamicin is a potential approach for improving therapeutic outcomes while reducing the toxicity in chemotherapy regimens. Improving survival outcomes for ALL patients will require better-defined patient populations that benefit the most from ADC therapies. Inotuzumab ozogamicin combined with a better understanding of ALL disease biology can potentially change the treatment paradigm for ALL patients, especially older patients and R/R cohorts, whose options remain limited.

Of note, both blinatumomab and inotuzumab ozogamicin are approved in R/R B-ALL, although key differences may make inotuzumab ozogamicin a better option for some patients. Blinatumomab is a BiTE construct that targets and activates $\mathrm{CD} 3+\mathrm{T}$ cells against $\mathrm{CD} 19+$ cells. ${ }^{1}$ Blinatumomab is administered in a 28-day continuous infusion, requiring admissions for the first 9 days of the first cycle and the first 2 days of the other cycles, then a pump at home in contrast to inotuzumab ozogamicin's weekly injection schedule which can be given outpatient. Additionally, cytokine release and neurological toxicity are seen with blinatumomab. However, the higher risk of VOD, especially in transplant candidates, and liver side effects may limit inotuzumab ozogamicin use in some patients. ${ }^{1,7}$

Inotuzumab ozogamicin has already shown favorable results as monotherapy in $\mathrm{R} / \mathrm{R}$ patients, including those status post multiple lines of salvage therapy, compared with standard chemotherapy. More recent data in combination with low-dose chemotherapy show promise. It is well-tolerated with a better safety profile seen with the weekly regimen, and future data may better stratify patient risk factors for VOD. Inotuzumab ozogamicin combined with other therapies beyond chemotherapy could also potentially improve clinical outcomes. Currently, there are multiple ongoing clinical trials, such as inotuzumab ozogamicin and bosutinib combination therapy in Ph+ ALL (NCT02311998), inotuzumab ozogamicin as post-transplant therapy in patients at high risk of relapse (NCT03104491), and further studies looking specifically at younger patients (NCT02981628) and elderly patients (NCT03249870).

Moving from R/R ALL to frontline ALL treatment will allow inotuzumab ozogamicin, as well as novel therapies such as other monoclonal antibodies and CAR T cells, to be studied in uncompromised patients and against a more sensitive disease. Inotuzumab ozogamicin has recently been studied in the setting of frontline treatment with impressive 2-year OS. ${ }^{22}$ In the future, randomized trials of comparing inotuzumab ozogamicin with standard intensive therapy in new ALL patients may lead to inotuzumab ozogamicin as frontline therapy for ALL. ${ }^{22}$ Unfortunately, in adult ALL, even with high CR rates, the survival remains limited. As we continue to characterize the pathophysiology and molecular alterations in ALL and develop more targeted therapy as part of individualized treatment strategies, we hope for promising improvements in the outcomes and survival of ALL patients.

\section{Disclosure}

AMZ has consulted for and received honoraria from Pfizer on unrelated projects. The authors report no other conflicts of interest in this work.

\section{References}

1. Terwilliger T, Abdul-Hay M. Acute lymphoblastic leukemia: a comprehensive review and 2017 update. Blood Cancer J. 2017;7(6):e577.

2. Fielding AK. Current treatment of Philadelphia chromosome-positive acute lymphoblastic leukemia. Haematologica. 2010;95(1):8-12.

3. Huguet F, Leguay T, Raffoux E, et al. Pediatric-inspired therapy in adults with Philadelphia chromosome-negative acute lymphoblastic leukemia: the GRAALL-2003 study. J Clin Oncol. 2009;27(6):911-918.

4. Jabbour E, O'Brien S, Ravandi F, Kantarjian H. Monoclonal antibodies in acute lymphoblastic leukemia. Blood. 2015;125(26):4010-4016.

5. Kantarjian H, Thomas D, Jorgensen J, et al. Inotuzumab ozogamicin, an anti-CD22-calecheamicin conjugate, for refractory and relapsed acute lymphocytic leukaemia: a phase 2 study. Lancet Oncol. 2012;13(4):403-411.

6. Thota S, Advani A. Inotuzumab ozogamicin in relapsed B-cell acute lymphoblastic leukemia. Eur J Haematol. 2017;98(5):425-434.

7. Maino E, Bonifacio M, Scattolin AM, Bassan R. Immunotherapy approaches to treat adult acute lymphoblastic leukemia. Expert Rev Hematol. 2016;9(6):563-577.

8. Paul S, Rausch CR, Kantarjian H, Jabbour EJ. Treatment of adult acute lymphoblastic leukemia with inotuzumab ozogamicin. Future Oncol. 2017;13(25):2233-2242.

9. Shor B, Gerber HP, Sapra P. Preclinical and clinical development of inotuzumab-ozogamicin in hematological malignancies. Mol Immunol. 2015;67(2 Pt A):107-116.

10. Walker S, Landovitz R, Ding WD, Ellestad GA, Kahne D. Cleavage behavior of calicheamicin gamma 1 and calicheamicin T. Proc Natl Acad Sci U S A. 1992;89(10):4608-4612.

11. de Vries JF, Zwaan CM, De Bie M, et al. The novel calicheamicinconjugated CD22 antibody inotuzumab ozogamicin (CMC-544) effectively kills primary pediatric acute lymphoblastic leukemia cells. Leukemia. 2012;26(2):255-264. 
12. Ogura M, Hatake K, Ando K, et al. Phase I study of anti-CD22 immunoconjugate inotuzumab ozogamicin plus rituximab in relapsed/refractory B-cell non-Hodgkin lymphoma. Cancer Sci. 2012;103(5):933-938.

13. Advani A, Coiffier B, Czuczman MS, et al. Safety, pharmacokinetics, and preliminary clinical activity of inotuzumab ozogamicin, a novel immunoconjugate for the treatment of B-cell non-Hodgkin's lymphoma: results of a phase I study. J Clin Oncol. 2010;28(12):2085-2093.

14. Kantarjian H, Thomas D, Jorgensen J, et al. Results of inotuzumab ozogamicin, a CD22 monoclonal antibody, in refractory and relapsed acute lymphocytic leukemia. Cancer. 2013;119(15):2728-2736.

15. DiJoseph JF, Armellino DC, Boghaert ER, et al. Antibody-targeted chemotherapy with CMC-544: a CD22-targeted immunoconjugate of calicheamicin for the treatment of B-lymphoid malignancies. Blood. 2004;103(5):1807-1814.

16. Dijoseph JF, Dougher MM, Armellino DC, Evans DY, Damle NK. Therapeutic potential of CD22-specific antibody-targeted chemotherapy using inotuzumab ozogamicin (CMC-544) for the treatment of acute lymphoblastic leukemia. Leukemia. 2007;21(11):2240-2245.

17. Advani AS, Stein AS, Kantarjian HM, et al. A phase II study of weekly inotuzumab ozogamicin (INO) in adult patients with CD22-positive acute lymphoblastic leukemia (ALL) in second or later salvage. Blood. 2014;124(21):2255..

18. Kantarjian HM, DeAngelo DJ, Stelljes M, et al. Inotuzumab ozogamicin versus standard therapy for acute lymphoblastic leukemia. $N$ Engl J Med. 2016;375(8):740-753.
19. Jabbour E, Advani AS, Stelljes M, Stock W, Liedtke M, Gökbuget N. Efficacy and safety of inotuzumab ozogamicin (INO) in older patients with relapsed/refractory $(\mathrm{R} / \mathrm{R})$ acute lymphoblastic leukemia (ALL) enrolled in the phase 3 INO-VATE trial. J Clin Oncol (ASCO). 2016;34:7029.

20. Sasaki K, Jabbour EJ, O'Brien SM, et al. Phase II study of the salvage mini-hyper-CVD in combination with inotuzumab ozogamicin (INO) for adult patients with relapsed/refractory $(\mathrm{R} / \mathrm{R})$ acute lymphoblastic leukemia (ALL). Blood. 2016;128(22):1606.

21. Jabbour E, Ravandi F, Kebriaei P, et al. Salvage chemoimmunotherapy with inotuzumab ozogamicin combined with mini-hyper-CVD for patients with relapsed or refractory philadelphia chromosome-negative acute lymphoblastic leukemia: a phase 2 clinical trial. JAMA Oncol. 2018;4(2):230-234.

22. Kantarjian H, Ravandi F, Short NJ, et al. Inotuzumab ozogamicin in combination with low-intensity chemotherapy for older patients with Philadelphia chromosome-negative acute lymphoblastic leukaemia: a single-arm, phase 2 study. Lancet Oncol. 2018;19(2):240-248.

23. DeAngelo DJ, Jabbour E, Stelljes M, Liedtke M, Stock W, Gökbuget $\mathrm{N}$. Inotuzumab ozogamicin (INO) for relapsed/refractory $(\mathrm{R} / \mathrm{R})$ acute lymphoblastic leukemia (ALL) in the phase III INO-VATE trial: efficacy and safety by prior therapy. J Clin Oncol (ASCO). 2016;34:7028.

24. Jabbour E, O'Brien S, Sasaki K, et al. Frontline inotuzumab ozogamicin in combination with low-intensity chemotherapy (mini-hyper-CVD) for older patients with acute lymphoblastic leukemia (ALL). Blood. 2015;124(21):794.
Journal of Blood Medicine

\section{Publish your work in this journal}

The Journal of Blood Medicine is an international, peer-reviewed, open access, online journal publishing laboratory, experimental and clinical aspects of all aspect pertaining to blood based medicine including but not limited to: Transfusion Medicine; Blood collection, Donor issues, Transmittable diseases, and Blood banking logistics; Immunohematology; Artificial and alternative
Dovepress

blood based therapeutics; Hematology; Biotechnology/nanotechnology of blood related medicine; Legal aspects of blood medicine; Historical perspectives. The manuscript management system is completely online and includes a very quick and fair peer-review system. Visit http://www.dovepress.com/ testimonials.php to read real quotes from published authors. 